\title{
Personality Profiles Associated with Different Motivations for Playing World of Warcraft
}

\author{
Lindsay T. Graham and Samuel D. Gosling, PhD
}

\begin{abstract}
Gamers play massively multiplayer online role-playing games (MMORPGs) for a variety of reasons. For example, some gamers play primarily as a form of socialization, whereas others play to gain a sense of achievement. Past studies have shown that these motives are associated with individual differences such as gender and number of years spent playing online games. What other individual differences might affect why people play MMORPGs? Personality is known to be associated with in-game behaviors, raising the possibility of link between personality and gaming motives. The present study examines the relationship between gamers' Big Five personality traits and their motivations for playing World of Warcraft. Results reveal several links between a player's personality and gaming motivations. For instance, individuals playing to socialize tend to be high on extraversion, agreeableness, neuroticism, and openness, whereas individuals playing to gain a sense of achievement tend to be high on extraversion and neuroticism, but low on agreeableness and conscientiousness. Findings are discussed with respect to previous research on links between personality and motives in other MMORPGs and in terms of how and why the connections between personality and motives may differ across online and offline contexts.
\end{abstract}

\section{Introduction}

$\mathbf{M}$ ASSIVELY MULTIPLAYER online role-playing games (MMORPGs) are games in which individuals play with and against other individuals in virtual worlds via the Internet. One of the most popular MMORPGs is World of Warcraft (WoW), which in 2008 (the latest date for which data are available) had an estimated 11 million subscribers. ${ }^{1}$ WoW is a fantasy-based game in which users can play alone (solo) or in groups (i.e., guilds) as mythical characters (e.g., orcs, elves, and gnomes) working to defend the fantasy world of Azeroth. As they travel across Azeroth, players can complete tasks such as earn gold (the currency used within the world), battle vicious creatures and other players, explore environments in WoW, and acquire enchanted items that allow players to take on increasingly difficult challenges.

The massive popularity of games such as WoW raises key questions regarding what it is that individuals get out of playing such games. Why do they play, and does everyone play for the same reasons? Recent reviews of the literature have revealed several motivations for playing MMORPGs. ${ }^{2-4}$ For example, according to Yee, ${ }^{4}$ gamers play MMORPGs to socialize with others (e.g., form relationships, provide and receive social support, and build collaborations), to gain a sense of achievement (e.g., acquire status, power, or domination over others), or to immerse themselves into a world outside the ordinary (e.g., explore virtual worlds, construct virtual identities, or escape the realities of the offline world and relax). These motivations differ across gender, with men more likely to play to achieve and manipulate others, and women more likely to play to satisfy relationship-related motives. ${ }^{5}$ Another study of gaming motives identified seven motivations for playing MMORPGs: social, escape, competition, coping, skill development, fantasy, and recreation. ${ }^{3}$ These dimensions overlap strongly with those found by Yee. ${ }^{4}$ For example, the dimensions of escape, coping, recreation, and fantasy would fall under Yee's broader immersion dimension. The Demetrovics et al. ${ }^{3}$ motivations of skill development and completion fall under Yee's ${ }^{4}$ achievement dimension, and the Demetrovics et al.' $\mathrm{s}^{3}$ social dimension aligns with Yee's ${ }^{4}$ social dimension.

The dimensions identified by $\mathrm{Yee}^{4}$ and by Demetrovics et al. $^{3}$ captured motives to play MMORPGs generally. A study focused on WoW players specifically identified two factors reflecting socialization and achievement motivations similar to two factors found in Yee's more general study, ${ }^{5}$ and two more-exploration and dissociation that essentially split up components that were grouped together in Yee's immersion factor. ${ }^{6}$ These factors were associated with variables such as age, years playing the game, and hours spent playing. These differences across groups raise the question of whether

Department of Psychology, The University of Texas at Austin, Austin, Texas. 
other individual differences-such as attitudes or personality traits-might be associated with player motivations too. Chang and Zheng ${ }^{7}$ found that individuals who are highly materialistic are more motivated to play online games than those that are not. If a materialistic attitude can predict individuals' motivations to play, what links might be present between player motives and broader personality traits such as extraversion or neuroticism?

Previous research shows that individuals express their personalities in MMORPGs, just as they do in other virtual environments (e.g., Facebook, personal Websites, and blogs). ${ }^{8}$ Specifically, a player's standing on the Big Five personality traits (extraversion, agreeableness, conscientiousness, neuroticism, and openness) is associated with his or her behaviors while in the game. ${ }^{8}$ For instance, compared with introverts, extraverts change guilds more often, and they prefer group activities. Conversely, introverts prefer solo activities and are more likely to have vanity pets (silent pet-like companions). ${ }^{8}$ The fact that personality is related to in-game behaviors suggests that personality could also be related to the motivations to play. Indeed, researchers looking at gaming motivations have called for more research examining the connections between the motivations and personality. ${ }^{3}$

Some relevant research has been undertaken in the broader domain of online games in general, which in addition to roleplaying games encompasses a broad swathe of games ranging from sports and puzzles to strategy and simulation. The two studies to examine these links have yielded some provocative findings, which raise a number of questions regarding how personality and motivations might be linked in the narrower domain of MMORPGs.

Using some subscales from Yee's ${ }^{4}$ motivational dimensions (i.e., discovery, role-playing, teamwork, advancement, and escapism), Jeng and Teng ${ }^{9}$ identified links between personality and motivations for playing online games in general. For instance, extraverts tend to be motivated by teamwork, as are those who are emotionally stable. ${ }^{9}$ Somewhat surprisingly, agreeableness proved to be related only to advancement-a motive one might expect to be associated with conscientiousness in the offline world, and conscientiousness, a trait usually associated with discipline, order, and attention to detail in one's environment, was positively associated with the motivation to escape reality. ${ }^{9}$ Also, as one might expect, openness, a trait associated with trying new things and new experiences, was associated with role-playing and discovery. ${ }^{9}$ In comparison to expectations of what trait-motive relationships might look like in the offline world, some of these findings are quite surprising and raise an interesting question-are some traitmotive relationships different online than they are offline?

Park, Song, and Teng ${ }^{10}$ also identified a series of links between player personality and motivation to play online games in general; however, the ways in which traits were associated with motives for playing differed from those of Jeng and Teng. ${ }^{9}$ Specifically, links emerged between personality and player motivations for just two of the Big Five traits: extraversion and agreeableness. ${ }^{10}$ Persons high on extraversion were motivated by adventure, escapism, relaxation, and achievement. ${ }^{10}$ Individuals high on agreeableness were also motivated by adventure, escapism, and achievement, but not relaxation. ${ }^{10}$ The discrepancies between the Park et al. ${ }^{10}$ and the Jeng and Teng ${ }^{9}$ studies may be due to the way in which motivation was measured. For example, Jeng and Teng ${ }^{9}$ used single items to measure five subscales (i.e., discovery, roleplaying, teamwork, escapism, and advancement) of Yee's Motivations for playing MMORPG scale, ${ }^{4}$ where as Park, Song, and Teng ${ }^{10}$ implemented a multimethod approach to construct a motivation scale that consisted of five different motivational dimensions for playing MMORPGs (i.e., relationship, adventure, relation, escapism, and achievement).

The inconsistency across studies in motive measurement appears to be a pervasive problem in this literature. In their extensive literature review, Boyle et al. ${ }^{2}$ identified several different sampling methods, assessment methods, and theoretical frameworks. When studies measure and define motives in different ways, it becomes difficult to compare findings across samples. Also, in many cases, one motive, such as socialization, ${ }^{11,12}$ has been the only focus of study making it difficult to conclude what other variables might have been influencing the findings. Most studies have investigated links between motives and individual differences within very broad contexts, such as online games or MMORPGs in general. However, the goals, aesthetics, and general character of games differ enormously from game to game, so it is surprising that there are only a few studies that focus on specific games (e.g., EverQuest $2^{13}$ ).

The present study sought to build on previous research by examining the degree to which game-playing motivations (e.g., socialization, achievement, and immersion) are associated with personality traits in the most popular MMORPG, WoW. The present findings also raise the question of how links between motives and personality traits may differ depending upon the online environment (i.e., WoW vs. MMORPGs in general) and even how the links may differ across offline and online worlds.

This study is exploratory, but we do expect certain relationships to emerge between motives and traits. For instance, we expect traits that aid relationship building (e.g., extraversion) to be positively related to socialization motivations. We also expect that traits important for completing tasks (e.g., conscientiousness) to be positively related to achievement motives. Finally, we expect those traits that might foster the ability for one to lose oneself within an experience (e.g., openness, which has been associated with absorption ${ }^{14}$ ) to be positively related to immersive motives.

\section{Method}

About 1,413 (166 women) WoW players participated in this study (mean age $=26.04, S D=7.50$ ). Users were recruited via an advertisement posted on a popular news Website for the WoW community, The WoW Insider (www.wowinsider .com/). Participants completed the self-reports of personality and motivations for playing the game. Additionally, players reported their occupation, character name, the average number of hours per week they played the game, and how long they had played. On average, participants played WoW $23.69(S D=14.37)$ hours per week and had played for 19.9 months $(S D=9.54)$ at the time of sampling. After participation, users were entered into a raffle that gave away 25 pieces of gold-the currency used within WoW.

\section{Instruments}

Users completed the 44-item Big Five Inventory, ${ }^{15}$ which measures the Big Five personality dimensions (extraversion, 
conscientiousness, agreeableness, neuroticism, and openness to experience). The Big Five were measured on a 1-to-five (strongly disagree to strongly agree, respectively) Likert scale; the Big Five means were $3.17(S D=0.82)$ for extraversion, 3.46 $(S D=0.67)$ for conscientiousness, $3.72(S D=0.62)$ for agreeableness, $2.59(S D=0.79)$ for neuroticism, and $3.92(S D=0.54)$ for openness. Results yielded Cronbach's alphas of 0.87 for extraversion, 0.78 for agreeableness, 0.82 for conscientiousness, 0.84 for neuroticism, and 0.75 for openness.

Participants also completed a modified version of Yee's ${ }^{4}$ scale, Motivations for Play in Online Games. This scale measures motivations for any type of online game, so we selected and adapted the questions we viewed as specifically relevant to WoW. Ultimately, six items measuring socialization, two items measuring achievement, and nine items measuring immersion were derived from Yee's ${ }^{4}$ original scale. Additionally, three new questions were added to the final survey. These items were generated from results of a pilot study in which five undergraduate WoW players participated in semistructured interviews. In the interviews, undergraduates were asked how often, when, for what purpose, and in what ways they played WoW. Two topics emerged from the interviews that were unaccounted for in the Yee ${ }^{4}$ scaleleadership motivation and expression of independence. Two items were generated to assess leadership motivation (I enjoy leading groups of other players; I often take charge of things when grouped), and one item was generated to assess expression of independence (I value independence in my character). The resulting questionnaire consisted of 20 items.

The Cronbach's alphas for the motivation scales were 0.75 for social, 0.47 for achievement, 0.65 for immersion, and 0.82 for leadership. The independence measure consisted of only one item, so Cronbach's alpha could not be computed. Reliability analyses revealed that one of the items measuring immersion was only weakly correlated with the other items (corrected item total correlation $=0.15$ ), so we removed it from the scale, resulting in an 8-item scale (Cronbach's alpha $=0.66$ ). Participant motivation was assessed on a 1-to-5 (strongly disagree to strongly agree respectively) Likert scale, and scores were calculated by averaging items for each motivation. Motivation means were $3.65(S D=0.73), 3.89$ $(S D=0.67), 3.13(S D=0.60), 3.54(S D=0.90)$, and $4.03(S D=$ 0.88) for socialization, achievement, immersion, leadership, and independence, respectively.

Raw correlations (along with correlations corrected for attenuation) between the personality scales and motivation scales are presented in Supplementary Table S1(Supplementary Data are available online at www.liebertpub.com/cyber).

\section{Results}

Participants' Big Five scores were regressed onto their scores for the five different motivations (See Table 1). Given the previous research showing gender differences in motivations for playing MMORPGs, 4,5 we also ran all the analyses controlling for gender (available upon request from corresponding author). However, the findings were virtually identical across analyses, so we report here the simpler findings that did not control for gender.

As expected, individuals motivated to play WoW for the purpose of socialization tended to be high on extraversion. Additionally, individual's playing WoW to socialize were relatively high on agreeableness, neuroticism, and openness, but low in conscientiousness. Approximately $10 \%$ of the variance in social motivations was accounted for by the Big Five.

Contrary to our hypothesis, achievement motivation was negatively related to conscientiousness. Achievement motivation of WoW players was also negatively related to agreeableness and openness, but positively to extraversion and neuroticism. Approximately $5 \%$ of the variance in achievement motivation was accounted for by the Big Five traits.

As expected, individuals playing WoW for immersive motives were relatively high in openness. Those motivated to immerse themselves in the game were also relatively high on neuroticism and agreeableness, but lower on extraversion and conscientiousness. Approximately $10 \%$ of the variance in immersion motives was accounted for by Big Five traits.

WoW gamers motivated to play for leadership purposes tended to be extraverted, conscientious, and open, and lower in agreeableness and neuroticism. Approximately 15\% of the variance in leadership motivation was accounted for by the Big Five.

Individuals with motives of independence tended to be low in extraversion, agreeableness, conscientiousness, and neuroticism, but high in openness. Approximately 3\% of the variance in independence motivation was accounted for by the Big Five.

\section{Discussion}

Here we examined the associations between motivations for playing the MMROPG, WoW, with personality traits. We found evidence linking the motivations to the personalities of

Table 1. Personality Traits as Predictors for Motivations in Playing World of Warcraft

\begin{tabular}{|c|c|c|c|c|c|c|c|c|c|c|}
\hline \multirow[b]{2}{*}{ Traits } & \multicolumn{2}{|c|}{$\begin{array}{c}\text { Social } \\
\text { motivations }\end{array}$} & \multicolumn{2}{|c|}{$\begin{array}{c}\text { Achievement } \\
\text { motivations }\end{array}$} & \multicolumn{2}{|c|}{$\begin{array}{l}\text { Immersive } \\
\text { motivations }\end{array}$} & \multicolumn{2}{|c|}{$\begin{array}{l}\text { Leadership } \\
\text { motivations }\end{array}$} & \multicolumn{2}{|c|}{$\begin{array}{l}\text { Independence } \\
\text { motivations }\end{array}$} \\
\hline & $B$ & $(S E)$ & $B$ & $(S E)$ & $B$ & $(S E)$ & B & $(S E)$ & $B$ & $(S E)$ \\
\hline Extraversion & $0.20^{* *}$ & 0.02 & $0.17^{* *}$ & 0.03 & $-0.07^{* *}$ & 0.02 & $0.45^{* *}$ & 0.03 & -0.02 & 0.03 \\
\hline Agreeableness & $0.23^{* *}$ & 0.03 & $-0.14^{* *}$ & 0.04 & 0.05 & 0.03 & $-0.15^{* *}$ & 0.05 & -0.06 & 0.04 \\
\hline Conscientiousness & -0.02 & 0.03 & $-0.12^{* *}$ & 0.04 & $-0.07^{* *}$ & 0.03 & $0.11^{* *}$ & 0.04 & -0.03 & 0.04 \\
\hline Neuroticism & $0.15^{* *}$ & 0.03 & $0.10^{* *}$ & 0.04 & $0.19^{* *}$ & 0.02 & -0.06 & 0.04 & 0.02 & 0.03 \\
\hline Openness & $0.11^{* *}$ & 0.04 & $-0.12^{*}$ & 0.05 & $0.21^{* *}$ & 0.03 & $0.13^{* *}$ & 0.05 & $0.28^{* *}$ & 0.05 \\
\hline$R^{2}$ & 0.10 & & 0.05 & & 0.10 & & 0.15 & & 0.03 & \\
\hline
\end{tabular}

${ }^{* *} p \leq 0.01$

${ }^{*} p \leq 0.05$.

$\mathrm{B}$, unstandardized beta; SE, standard error. 
gamers. Our results indicate that each motivation for playing is associated with a different combination of personality traits.

As increasing numbers of people engage in virtual environments on a daily basis, it becomes more important to understand who is spending time in these spaces and why. Individuals select and manipulate their daily environments in the offline world to suit their needs, ${ }^{16}$ so it is reasonable to assume that they also do so in the online world. There are numerous kinds of virtual environments (e.g., social networking sites, blogs, and games) in which individuals spend large amounts of time, each with its own set of goals, possibilities, and norms. Therefore, it is important to examine patterns of findings at a domain-specific level. We focused on WoW because of the high number of individuals interacting in the game.

The present findings demonstrate that individuals not only have different motivations for interacting in WoW, but that their personality traits are associated with those motivations. Winter et al. ${ }^{17}$ present evidence for associations between traits and motives, arguing that both are essential to understand the make-up of an individual's personality and how he or she relates to his or her environment. Winter et al. ${ }^{17}$ suggest that traits essentially act as a channel through which individuals' motives can be expressed in daily life. The current results point to the possibility that an individual's traits act as a medium through which his or her motivations can be expressed in online worlds, just as they are in offline environments.

Comparisons between the present findings and those found previously in the broader domain of MMORPGs in general suggest that domain-specific patterns are not reflected in findings from domain-general studies. Therefore, future work should examine the connections between traits and motives in other online contexts as well, such as other MMORPGs (such as Second Life or Everquest) or other virtual environments (such as blogs or social networking sites).

Moving forward, work should seek to compare how the relationships between traits and motives in the offline world compare to those found in the online world. For example, the present findings yielded some surprising results in regard to conscientiousness. Contrary to what one might expect in the offline world, we found that individuals concerned with gaining a sense of achievement in the game of WoW were low in conscientiousness, not high. One possible explanation is that MMORPGs serve as a leisure pursuit or procrastination strategy that detracts away from one's offline activities, such that high-achievement-motivated individuals would be less likely to play these games. However, the correlation between achievement motivation and hours of play was positive $(r=0.24 ; p=0.000)$, suggesting that there may be differences in how motivations are expressed in online-versus-offline environments. This finding suggests that traits that are advantageous for achieving tasks in offline environments might not have the same function in online environments. Perhaps, there is something unique about online environments that helps fulfill different needs than offline environments do. In other words, perhaps achievement motivation within the context of WoW (which is what was measured in this study) is unrelated, or even negatively related, to broader measures of achievement motivation, which tends to be positively related to conscientiousness. ${ }^{18}$ The present data do not allow us to test this possibility. Therefore, future research should look at how achievement motivations play out differently in offline and online worlds. Note that it is unlikely that our finding is spurious, because similar patterns were also identified in the broader studies. ${ }^{9,10}$

To begin understanding the differences between offline and online spaces researchers could examine how people influence their environments to meet their daily needs. Gosling ${ }^{19}$ suggests a framework for understanding how individuals intentionally and unintentionally manipulate their environments. People want to broadcast information about themselves; they want to influence how they think and feel; and they inadvertently affect their environments with their daily behaviors. ${ }^{19}$ These forms of expression have been recorded in a variety of contexts (e.g., bedrooms, offices, and social networking sites), but it is not yet known if people have these modes of self-expression in their virtual worlds too.

Past work suggests that players of MMORPGs create avatars that are characterizations of their ideal selves, rather than their true selves. ${ }^{20}$ These findings differ from those of Back et al., ${ }^{21}$ who found that individuals using the social networking sites, Facebook and StudiVZ portray accurate images of their true selves online, not just favorable images of their ideal selves. The discrepancy in findings across these two online domains suggests that self-expression and the ways individuals interact within virtual environments can differ depending on the virtual domain. For example, previous research has shown that email addresses provide valid clues to the identity of the person who created it, ${ }^{22}$ but that WoW usernames do not. ${ }^{23}$ One feature that distinguishes many MMORPGs from other online and offline contexts is that in MMORPGs, interactions can occur with little accountability and little expectation of subsequent offline interactions; perhaps, this difference ends up being a critical factor in driving the psychological processes expressed in WoW and other MMORPGs.

Some work has begun looking at how personality is manifested in virtual spaces (see ${ }^{24}$ for a review), including WoW, ${ }^{4}$ but there is still much to be explored. Research is needed to pinpoint what features make virtual domains (e.g., MMORPGs, Facebook, blogs, and dating sites) different from one another, and how those differences affect the use and motives of the user. Researchers also need to look at how the expressive behaviors in these spaces relate to individuals' motives in online environments. Such data can augment the present findings to help provide a rich understanding of why and how people engage in MMORPG behavior. The present findings suggest that this understanding must be sensitive to the variation in people and motives that drive online gameplaying behavior.

\section{Acknowledgments}

We would like to thank Jim Casio, Ann Dragovits, Rick Gove, Jefferson Leard, and Tam Nguyen for their insightful comments in the beginning stages of this study, and Austin Harley for his help collecting the data. We would also like to thank Gabriella Harari for her useful comments on this manuscript.

\section{Author Disclosure Statement}

No competing financial interests exist. 


\section{References}

1. White P. (2008) MMOGData: charts. 2009. http://mmogdata .voig.com (accessed Feb. 5, 2012).

2. Boyle EA, Connolly TM, Hainey T, et al. Engagement in digital entertainment games: a systematic review. Computers in Human Behavior 2012; 28:771-780.

3. Demetrovics Z, Urban R, Nagygyorgy K, et al. Why do you play? The development of the motives for online gaming questionnaire (MOGQ). Behavior Research Methods 2011; 43:814-825.

4. Yee N. Motivations of play in online games. Journal of CyberPsychology and Behavior 2007; 9:772-775.

5. Yee N. The demographics, motivations, and derived experiences of users of massively-multiuser online graphical environments. PRESENCE: Teloperators and Virtual Environments 2006; 15:309-329.

6. Fuster H, Oberst U, Griffiths MD, et al. Psychological motivation in online role playing games: a study of Spanish World of Warcraft players. Anales de Psicologia 2012; 28: 274-280.

7. Chang JH, Zheng $\mathrm{H}$. Analyzing online game players: from materialism and motivation to attitude. CyberPsychology and Behavior 2008; 11:711-714.

8. Yee N, Ducheneaut N, Nelson L, Likarish P. Introverted elves and conscientious gnomes: the expression of personality in World of Warcraft. In Proceedings of Conference on Human Factors in Computing Systems 2011; 753-762.

9. Jeng SP, Teng CI. Personality and motivations for playing online games. Social Behavior and Personality 2008; 38: 1053-1060.

10. Park J, Song Y, Teng CI. Exploring the links between personality traits and motivations to play online gmaes. Cyberpsychology, Behavior, and Social Networks 2011; 14: 747-751.

11. Cole H, Griffiths MD. Social interactions in massively multiplayer online role-playing games. CyberPsychology and Behavior 2007; 10:575-583.

12. Hussain Z, Griffiths MD. Gender swapping and socializing in cyberspace: an exploratory study. CyberPsychology and Behavior 2008; 11:47-53.

13. Williams D, Yee N, Caplan S. Who plays, how much, and why? Debunking the stereotypical gamer profile. Journal of Computer-Mediated Communication 2008; 13:9931018.
14. Glisky ML, Tataryn DJ, Tobias BA, et al. Absorption, openness to experience, and hypnotizability. Journal of Personality and Social Psychology 1991; 60:263-272.

15. John OP, Srivastava S. (1999) The big five trait taxonomy: history, measurement and theoretical perspectives. In: Pervin LA, John OP, eds. Handbook of personality: theory and research. New York: Guilford Press, pp. 102-138.

16. Buss DM. Selection, evocation, and manipulation. Journal of Personality and Social Psychology 1987; 53:1214-1221.

17. Winter DG, John OP, Stewart AJ, et al. Traits and motives: toward an integration of two traditions in personality research. Psychological Review 1998; 102:231-250.

18. Busato VV, Prins FJ, Elshout JJ, et al. Intellectual ability, learning style, personality, achievement motivation and academic success of psychology students in higher education. Personality and Individual Differences 2000; 29:1057-1068.

19. Gosling SD. (2008) Snoop: what your stuff says about you. New York: Basic Books.

20. Bessiere K, Seay AF, Kiesler S. The ideal elf: identity exploration in World of Warcraft. CyberPsychology and Behavior 2007; 10:530-535.

21. Back MD, Stopfer JM, Vazire S, et al. Facebook profiles reflect actual personality, not self-idealization. Psychological Science 2010; 21:372-374.

22. Back MD, Schmukle SC, Egloff B. How extraverted is honey .bunny77@hotmail.de? Inferring personality from e-mail addresses. Journal of Research in Personality 2008; 42:1116-1122.

23. Graham LT, Gosling SD. Impressions of World of Warcraft players' personalities based on their usernames: consensual but not accurate. Journal of Research in Personality 2012; 46:599-603.

24. Graham LT, Sandy CJ, Gosling SD. (2011) Manifestations of personality in physical and virtual environments. In: ChamorroPremuzic T, Fumham A, von Stumm S, eds. Handbook of individual differences. Oxford: Whiley-Blackwell, pp. 773-800.

Address correspondence to: Lindsay T. Graham Department of Psychology The University of Texas at Austin 1 University Station A8000 Austin, TX 78712

E-mail: lindsaytgraham@gmail.com 